\title{
Indicadores Sociais: Um Estudo Realizado nos Balanços Sociais de Empresas que Receberam o Selo IBASE ${ }^{1}$
}

\author{
Ana Paula Ferreira da Silva \\ Abani José Ribeiro de Lima ${ }^{3}$ \\ Erica Xavier de Souza \\ Jairo Pereira ${ }^{5}$
}

\section{RESUMO}

O presente trabalho discute os indicadores de balanços sociais utilizados pelas empresas que receberam o Selo do Instituto Brasileiro de Análises Sociais e Econômicas (IBASE). Como principal objetivo, este trabalho procurou investigar quais são os indicadores sociais utilizados para evidenciar as práticas sociais voltadas para os funcionários, para com a sociedade, bem como para com o meio ambiente. Após a introdução deste artigo, encontra-se um breve retrospecto histórico sobre o Balanço Social no mundo e no Brasil, a descrição do modelo IBASE de balanço social e do selo IBASE. Para a realização deste estudo foi realizada uma pesquisa documental em 132 balanços sociais, que receberam o selo IBASE de balanço social no período de 2005 a 2007, os quais estavam disponíveis no site denominado balançosocial.org. Os resultados da pesquisa demonstram que as empresas recebedoras do selo IBASE de balanço social utilizaram mais indicadores sociais voltados para demonstrar a relação da entidade com os seus recursos humanos, incluindo os indicadores do corpo funcional, seguindo com a sociedade e por último o meio ambiente, sendo, dezessete (17), dez (10) e três (3) indicadores respectivamente. Por fim, concluiu-se que as empresas que receberam o selo IBASE de balanço social apresentam através de um conjunto de indicadores padrões suas praticas de ações de responsabilidade Social.

Palavras-Chave: Balanço Social; Selo IBASE; Indicadores Sociais; Responsabilidade Social.

\begin{abstract}
This paper discusses the social audits indicators used by companies that received the seal of the Brazilian Institute of Social and Economic Analyses (IBASE). The main objective of this study is to investigate what are the social indicators used to assess the social practices aimed at employees, to society and to the environment. After the introduction, is a brief historical overview of the Social Balance in the world and in Brazil. The IBASE description model of the social and IBASE seal. For this study a survey was conducted in 132 social balances, which received the IBASE seal in its Social Balance from 2005, until 2007. They were available at the site named balançosocial.org. The survey results shown that companies recipients IBASE seal in their Social Balance, used more social indicators aimed to demonstrate the relationship of the entity with its human resources, including the staff indicators, following the company and ultimately the environment being seventeen (17), ten (10) and three (3) indicators respectively. Finally, we conclude that the companies who received the IBASE seal in its Social Balance presented a similar series of standard practices of their social responsibility.
\end{abstract}

Keywords: Social audits; IBASE Seal; Social Indicators; Social Responsibility.

\footnotetext{
${ }^{1}$ Artigo apresentado e publicado nos anais do Simpósio de Engenharia de Produção, 2011. Artigo recebido em 17.01.2012. Revisado por pares em 07.03.2012 (blind review). Recomendado para publicação em 12.03.2012 por José Ribamar Marques de Carvalho (Editor). Publicado em 24.03.2012. Organização responsável pelo periódico: UACC/UFCG.

${ }^{2}$ Mestre em Administração, Instituição: Faculdade Boa Viagem (FBV), e-mail: anapafesilva@ hotmail.com

${ }^{3}$ Graduada em Ciências Contábeis, Instituição Faculdade de Boa Viagem, e-mail: albanylima@ yahoo.com.br

${ }^{4}$ Mestre em Administração, Instituição Faculdade de Boa Viagem, e-mail: exsouza@ yahoo.com.br

${ }^{5}$ Mestre em Administração, Professor da Universidade Municipal de São Caetano do Sul , e-mail: jairopb@uol.com.br
}

REUNIR - Revista de Administração, Contabilidade e Sustentabilidade - Vol. 2, nº 1, p.72-86, Jan-Abr/2012. 


\section{INTRODUÇÃO}

Durante séculos, o principal usuário da contabilidade foi o proprietário do negócio, o gestor individual. As demonstrações contábeis eram elaboradas com a finalidade de atender as demandas internas dos gestores. Entretanto, com o desenvolvimento das organizações, e com o surgimento dos credores que passariam a ser parceiros dos negócios, as exigências quanto às informações contábeis cresceram progressivamente, especialmente aquelas que apontavam a capacidade da empresa em honrar seus compromissos. Num segundo momento, o Estado também, a partir do século XVII, sobretudo na França, passou a exigir as informações contábeis com o fim de exercer um controle tributário, visando à arrecadação de impostos. Além destes fatores mencionados, com o nascimento de grandes empresas nos ramos Ferroviário, Têxtil, Siderurgia e de Construção de Estradas, tornou-se necessário um alto investimento, implicando em uma maior abertura das organizações, tornando deste modo, as informações contábeis, um elemento de grande exigência.

Desta maneira, a contabilidade ampliou suas informações, atendendo a seus novos usuários, evidenciando assim, o desempenho econômico e financeiro das empresas. A partir da década de 60, os trabalhadores da Europa e dos Estados Unidos, começaram a exigir das organizações informações econômicas e sociais. Principalmente, relativas às questões trabalhistas, tendo em vista, a discussão sobre a responsabilidade social, dando origem à implantação do Balanço Social em 1977 na França, que demonstrava apenas dados sobre os recursos humanos (CANZIAN, 2005).

Presentemente, a sociedade como um todo, tem cobrado das organizações e do Estado, documentos que demonstrem seus investimentos nos campos, econômico e social, tomando como base a idéia de que as empresas consomem recursos naturais, renováveis ou não, que integram o patrimônio da humanidade, além de utilizarem recursos humanos, físicos e tecnológicos que pertencem à sociedade. Essa requisição tem como finalidade, observar a utilização eficaz e responsável destes recursos.

Portanto, nos últimos anos, especialmente na Europa, para atender as reivindicações apontadas no parágrafo anterior, tem-se observado a elaboração de uma nova demonstração, a partir da contabilidade, através da qual foi denominada Balanço Social (BS), que evidencia como e quanto de recursos as instituições aplicaram em prol dos colaboradores, da comunidade e do meio ambiente. Elaborar o Balanço Social significa uma grande contribuição para a consolidação de uma sociedade verdadeiramente democrática.

O principal objetivo deste trabalho foi investigar quais são os indicadores sociais utilizados para evidenciar as práticas sociais voltadas para os funcionários, para com a sociedade, bem como para com o meio ambiente. Para a realização desta investigação, pretendeu-se alcançar os seguintes objetivos específicos: a) levantar discussões sobre o conceito, objetivos e importância do balanço social, bem como identificar sua evolução no Brasil e no mundo; b) descrever a estrutura e as principais características do modelo de balanço social, proposto pelo Instituto Brasileiro de Análises Sociais e Econômicas (IBASE); c) investigar quais são os principais indicadores sociais utilizados pelas empresas que receberam o Selo IBASE nos anos de 2005, 2006 e 2007.

Este trabalho está estruturado em oito seções, iniciando com esta introdução. Nas quatro seções seguintes aborda a fundamentação teórica, com destaque às temáticas: balanço social, modelo IBASE de balanço social, Selo IBASE para Balanços Sociais. Em seguida é apresentada a quarta seção, que procura descrever a metodologia adotada. Na sequência apresenta os resultados e as conclusões obtidas com a realização deste estudo.

REUNIR - Revista de Administração, Contabilidade e Sustentabilidade - Vol. 2, nº 1, p.72-86, Jan-Abr/2012. 


\section{REFERENCIAL TEÓRICO}

\subsection{Balanço Social: conceito, objetivo e forma de divulgação}

O Balanço Social também é conhecido como: Relatório de Sustentabilidade Empresarial, Balanço Social Corporativo, Relatório Social e Relatório Social-Ambiental, dentre outros. Este instrumento tem por objetivo designar os materiais informativos sobre a situação da empresa em relação a questões sociais e ambientais. Para KROETZ (2000, p.136)

O Balanço Social representa a demonstração dos gastos e das influências (favoráveis e desfavoráveis) recebidas e transmitidas pelas entidades na promoção humana, social e ecológica. Os efeitos dessa interação dirigem-se aos gestores, aos empregados e á comunidade, no espaço temporal passado/presente/futuro, tornandose parte integrante da chamada Contabilidade Social que está em fase de desenvolvimento.

Kraemer e Tinoco (2008, p. 87) entendem que: "Balanço Social é um instrumento de gestão e de informação que visa evidenciar de forma mais transparente possível, informações contábeis, econômicas, ambientais e sociais, do desempenho das entidades, aos mais diferenciados usuários".

Um dos objetivos do balanço Social é informar de forma mais transparente possível, as informações econômicas e sociais e o do desempenho das entidades, aos mais diferenciados usuários da contabilidade. Ou seja, é um instrumento de gestão estratégica, pois demonstra os investimentos realizados em benefício de seus colaboradores, da comunidade e de como é feita a distribuição da riqueza gerada.

Há vários formatos de divulgação do BS, sobre este fato Line, Hawlwy e Krut (2002, apud Oliveira, 2005, p.9) comentam que este demonstrativo pode "ser um documento separado ou integrado ao relatório anual da empresa. Com a expansão do uso da tecnologia de informação, a utilização da Internet a disponibilização dos balaços sociais tem crescido". Estudo realizado por Miranda et al (2001, p.6) em uma amostra de 29 empresas, 55\% das empresas brasileiras utilizam as notas explicativas como forma de publicação do BS, ficando os $45 \%$ restantes divulgados através de demonstrativo em separado, seguindo o formato do modelo do IBASE.

\subsection{Balanço Social (BS) no mundo: origem, modelos e obrigatoriedade}

O Balanço Social surgiu na Europa com a finalidade de atender os movimentos sociais que exigiam documentos que abordassem questões sobre projetos sociais, condições ambientais, informações para os empregados sob o aspecto do nível de emprego, condições de trabalho, remuneração e formação profissional.

No ano de 1972, a empresa Singer France, elaborou pela primeira vez um Balanço Socioeconômico (TREVISAN, 2002) e nos anos consecutivos, as experiências se multiplicaram. Em 1977, a lei sobre Balanço Social foi aprovada na França, garantindo definitivamente a necessidade de se expressar a importância dos trabalhadores no seio das empresas. Esta legislação estipula que empresas com 300 trabalhadores, ou mais, deveriam elaborar anualmente o Balanço Social (CUNHA; RIBEIRO, 2004). A lei por ser inédita, não contemplou uma série de informações de caráter econômico, que os demandantes gostariam de ver, como por exemplo, a geração do Valor Adicionado, item importante na análise macroeconomica.

REUNIR - Revista de Administração, Contabilidade e Sustentabilidade - Vol. 2, nº 1, p.72-86, Jan-Abr/2012. 
Nos países desenvolvidos, as informações sociais, geralmente demonstradas em um Balanço Social, são voluntárias em sua grande maioria. Como bons exemplos dessa prática, estão países como Alemanha, Espanha, Estados Unidos, Grã-Bretanha, Holanda e Suécia (CUNHA; RIBEIRO, 2004, p.5-6), todavia em outros países como França, Portugal e Bélgica, existe a obrigatoriedade legal para a elaboração do Balanço Social.

Cunha e Ribeiro (2004) estudando sobre os modelos de balanços sociais (francês, belga, e português), expressos de maneira sintética no quadro 1, constataram a presença de informações unicamente relacionadas com a área de Recursos Humanos, sem englobar as outras três vertentes: Valor Adicionado (exceto o modelo português, que contém a informação sobre o valor adicionado mas, não sua composição e cálculo), Ambiental, e Relações com a Sociedade.

\begin{tabular}{|c|c|c|c|}
\hline Ano & Pais & OBRIGATORIDADE & ESTRUTURA DO MODELO \\
\hline 1977 & França & $\begin{array}{l}\text { lei } 77.769 / 77 \text { obriga } \\
\text { as empresas públicas } \\
\text { e privadas com mais } \\
\text { de } 299 \text { empregados, } \\
\text { ou seja, a partir de } \\
300 \text { empregados a } \\
\text { elaborar anualmente o } \\
\text { Balanço Social }\end{array}$ & $\begin{array}{l}\text { O Balanço Social Francês ele e dividido em sete partes: 1- } \\
\text { voltado para o emprego; 2- remuneração e encargos; 3- } \\
\text { evidenciação de higiene e segurança; 4- evidenciação das } \\
\text { condições de trabalho; 5- evidenciação da formação } \\
\text { profissional; 6-relações profissionais; } 7 \text { - condição de vida de } \\
\text { dependentes da empresa. Em suma a lei Francesa que } \\
\text { caracteriza as informações que devem ser evidenciada no } \\
\text { Balanço Social foca basicamente em um único agente } \\
\text { beneficiário que são os seus colaboradores, os seus } \\
\text { funcionários. }\end{array}$ \\
\hline 1985 & Portugal & $\begin{array}{l}\text { Lei } \mathrm{n}^{\circ} .141 / 85 \\
\text { obrigando as } \\
\text { empresas com mais } \\
\text { de } 100 \text { funcionários } \\
\text { elaborarem o seu } \\
\text { Balanço Social }\end{array}$ & $\begin{array}{l}\text { O modelo português de Balanço Social foi baseado no modelo } \\
\text { Francês o mesmo esta dividido em cinco partes: } 1 \text { - voltado para } \\
\text { emprego; 2- custo com pessoal; } 3 \text { - higiene e segurança no } \\
\text { trabalho; 4- formação profissional; 5- proteção social } \\
\text { complementar. O principal usuário desse demonstrativo é o } \\
\text { ministério do emprego e da seguridade social que envia cópias } \\
\text { a associações, sindicatos dos empregados e outras que cuidam } \\
\text { da inspeção geral do trabalho (CUNHA, RIBEIRO, 2004). }\end{array}$ \\
\hline 1996 & Bélgica & $\begin{array}{l}\text { Através de decreto } \\
\text { para todas as } \\
\text { empresas desse país }\end{array}$ & $\begin{array}{l}\text { É dividido em quatro categorias sendo elas: estado das pessoas } \\
\text { aptas, movimento do pessoal durante o exercício, informação } \\
\text { sobre a manutenção e criação de emprego e formação dos } \\
\text { trabalhos durante o exercício (FREIRE, REBOUÇAS, 2001). } \\
\text { Apresenta um número pequeno de indicadores e limita suas } \\
\text { informações para a gestão de pessoas, bem como o modelo } \\
\text { francês e o português. }\end{array}$ \\
\hline
\end{tabular}

QUADRO 1 - Obrigatoriedade do Balanço Social no Mundo.

Fonte: Elaboração própria dos autores com base nos autores citados dentro do quadro.

\subsection{Origem Balanço Social (BS) no Brasil: origem, legislação e modelo IBASE}

As entidades cristãs tiveram uma grande participação no surgimento do balanço social no Brasil. No estado de São Paulo, datado em 1961, foi instituída a Associação dos Dirigentes Cristãos de Empresa (ADCE) para servir como um administrador operacional da Union Internationale Chrétienne de Dirigeants d'Enterprise (UNIPAc). Em 1965, a ADCE instituiu a Carta de Princípios do Dirigente Cristão de Empresas. Mas, somente no ano de 1974 é que efetivamente foi descoberta uma alusão ao balanço social. No ano de 1977, dentre os assuntos mais discutidos, estava o balanço social (RIZZI, 2002).

A Fundação Instituto de Desenvolvimento Empresarial e Social (FIDES), na década de 80, foi instituída pela ADCE com o propósito de promover e propagar as questões sociais nas

REUNIR - Revista de Administração, Contabilidade e Sustentabilidade - Vol. 2, nº 1, p.72-86, Jan-Abr/2012. 
organizações e ajudá-las nesse aspecto, elaborando um modelo de balanço social. Todavia, só foram iniciadas em meados de 90. Poucas empresas utilizaram os balanços e relatórios sociais, para evidenciar todas as obras executadas, fossem em benefício da sociedade, meio ambiente ou de seus próprios trabalhadores. Mansur e Torres (2008, p. 16) mencionam o início da utilização do Balanço Social, lembrando que:

O Balanço Social da Nitrofértil, empresa estatal situada na Bahia, realizado em 1984, é considerado o primeiro documento brasileiro do gênero, que assume o nome de Balanço Social. No mesmo período, estava sendo realizado o BS do Sistema Telebrás, publicado em meados dessa década. O Banespa publicou o seu em 1992, compondo a lista das empresas precursoras em BS no Brasil.

No Brasil não há nenhuma lei federal que obrigue as empresas a publicarem o chamado Balanço Social, todavia, existem resoluções contábeis, projetos de lei, legislações estaduais e municipais e algumas setoriais, no caso da Agencia Nacional de Energia Elétrica (ANEEL), que obrigam as empresas deste setor a publicarem seus balanços sociais desde o ano de 2003 dentro do modelo IBASE. Na esfera contábil há duas resoluções que orientam a elaboração do Balanço social. A primeira resolução surge com o Conselho Regional de Contabilidade do Rio de Janeiro, que através da Resolução CRC-RJ n 292/2001 "instituiu a possibilidade de recebimento do Certificado de Responsabilidade Social para as empresas situadas no estado do Rio de Janeiro que apresentarem o Balanço Social à sua apreciação" (CARVALHO; SIQUEIRA, 2009, p.100).

A outra resolução de caráter contábil foi editada em 2004 o Conselho Federal de Contabilidade, através da Resolução de $\mathrm{n}^{\circ} 1.003$, passando a estabelecer os procedimentos a serem adotados pelas instituições que optarem pelo balanço social. Essa resolução é mais conhecida como Norma Brasileira de Contabilidade Técnica número 15 (NBCT-15), a qual propõe um modelo de balanço social que deve demonstrar informações em quatro vertentes: geração e distribuição de riqueza, balanço de recursos humanos, a interação da entidade com a sociedade e a relação da entidade com o meio ambiente. Esta norma sugere um total de 48 indicadores, sendo oito (8) destes voltados para o meio ambiente, doze (12) indicadores de cunho negativo. Esta norma orienta que a organização poderá detalhar a informação que julgar importante, além de dispor que o balanço social deve ser assinado pelo responsável por sua elaboração e ser objeto de auditoria independente (CARVALHO; SIQUEIRA, 2009).

No âmbito federal existem dois projetos de lei, que versam sobre balanço social no Brasil, são eles: o projeto de lei no 32/1999 e o $n^{\circ}$ 1.035/2003. O projeto de lei de $n^{\circ} 32 / 1999$, do deputado Paulo Rocha, "propõe obrigatoriedade do Balanço Social para empresas privadas a partir de 100 empregados e para empresas públicas, de economia mista, permissionárias e concessionarias, independente do número de empregados" (CARVALHO; SIQUEIRA, 2009, p.100). Este projeto estabelece quarenta e quatro indicadores (44) distribuídos nas quatro (4) dimensões do BS: empregados (61\%), comunidade (25\%), empresa (7\%) e meio ambiente (7\%). Este projeto de lei não incentiva a exposição de indicadores de cunho negativo e nem faz menção sobre a utilização de notas explicativas, revisão do documento por terceiros, assinatura do responsável pela elaboração, bem como a apresentação de períodos comparativos.

O projeto de lei 1.305/2003 propõe um modelo de Balanço Social que não incluiria a Demonstração de Valor Adicionado (DVA), nem indicadores voltados para evidenciar a relação da empresa com o meio ambiente no modelo proposto de balanço social. Os indicadores propostos dão ênfase em se demonstrar a relação da empresa com os seus

REUNIR - Revista de Administração, Contabilidade e Sustentabilidade - Vol. 2, no 1, p.72-86, Jan-Abr/2012. 
recursos humanos, mesmo assim são considerados limitados para uma análise ampla das ações sociais da entidade no âmbito de sua relação com o corpo funcional, visto que solicita apenas os seguintes indicadores: número de empregados da sociedade empresária e admissões e demissões. É importante ressaltar que este projeto de lei também previa a necessidade do balanço social passar por uma auditoria independente (BRASIL, 2003).

Apesar das iniciativas de se regulamentar a publicação do BS a nível nacional não terem obtido sucesso, já que os projetos de lei nem chegaram a ir à votação em plenário, alguns Estados e Municípios conseguiram criar uma legislação incentivando a publicação do BS, através da concessão de prêmios e homenagens. Há três experiências de legislação na esfera estadual que trata sobre Balanço Social nos estados do Rio Grande do Sul, Mato Grosso e Amazonas, nos quais são definidos até mesmo a estrutura informativa dos Balanços Sociais.

A primeira experiência estadual deu-se no início do ano de 2000 , através da Lei $\mathrm{n}^{\circ}$ 11.400, que regulamentou juntamente com o Conselho Regional de Contabilidade do Rio Grande do Sul (CRC-RS) a possibilidade de instituir o 'Certificado de Responsabilidade Social', para empresas que apresentarem o BS no modelo proposto pela mesma. A Lei $11.440 / 2000$ previa a existência de trinta e quatro (34) indicadores voltados para evidenciar a relação da empresa com os empregados, o meio ambiente e a sociedade (comunidade). Todavia, esta lei deixa claro, que caso a empresa tenha interesse ou necessite poderá incluir outros indicadores. Dois desses indicadores são de 'cunho negativo' voltados para demonstrar a relação da entidade para com os seus colaboradores. Além disso, esta legislação obriga a assinatura do BS pelo contador responsável, mas não faz menção à utilização: de notas explicativas; de auditoria independente; bem como de que o BS deve ser apresentado em períodos comparativos, apesar dos indicadores proporcionarem a possibilidade de comparação entre os BS de empresas que utilizam o mesmo modelo (RIO GRANDE DO SUL, 2000).

A segunda legislação estadual sobre o BS foi expressa pela lei ${ }^{\circ} 7,687 / 2002$ do estado de Mato Grosso, a qual, assim como a lei 11.400/2000 no Rio Grande do Sul, regulamenta a instituição de um Certificado de Responsabilidade Social, neste caso para empresas privadas e organizações não governamentais (MATO GROSSO, 2002). Esta lei previu os mesmos indicadores e disposições já definidas pela lei do Rio Grande do Sul.

A terceira e última legislação estadual voltada para o BS é a lei $n^{\circ} 2.843 / 2003$, que, assim como as demais leis estaduais sobre o Balanço Social, possui as mesmas características apresentadas pela lei do BS no que tange: "a estrutura dos indicadores, no uso das notas explicativas e da auditoria independente; na apresentação de períodos comparáveis e possibilidade de comparação entre balanços sociais de diferentes empresas" (CARVALHO; SIQUEIRA, 2009, p.103).

Compreendendo a simplicidade como garantia do envolvimento de um número maior de corporações, o IBASE, em parceria com diversos representantes de empresas públicas e privadas, a partir de inúmeras reuniões e debates com vários setores da sociedade, desenvolveu um modelo que tem a vantagem de estimular todas as empresas a divulgar seu balanço social, independente do tamanho e setor. O Modelo de Balanço Social do IBASE é um "dos mais legitimados modelo utilizados no Brasil por ser um modelo simples e de fácil coleta de dados por parte dos gestores da organização" (TORRES, 2001, p.26). O Modelo IBASE de Balanço Social está estruturado em sete (7) grupos de informações conforme descrevem Bernardo, Silva e Falk (2011, p.7 ):

1. Informações financeiras ou Base de cálculo - Divulgam os valores da Receita Líquida, do Resultado Operacional e da Folha de Pagamento Bruto. Tais valores

REUNIR - Revista de Administração, Contabilidade e Sustentabilidade - Vol. 2, nº 1, p.72-86, Jan-Abr/2012. 
serão utilizados para calcular os percentuais nos demais itens. Por exemplo: a receita líquida, resultado operacional, folha de pagamento bruta e o valor adicionado;

2. Indicadores sociais internos ou indicadores laborais - Demonstram os gastos realizados com os funcionários das empresas, tais como: alimentação, encargos sociais compulsórios, previdência, saúde, educação, alimentação, auxílio creche e participação nos resultados;.

3. Indicadores sociais externos - Mostram os gastos realizados com projetos voltados para a sociedade, explicita o benefício que a organização realizou com a mesma. Dentre eles estão: educação, alimentação, esporte e cultura.;

4. Indicadores ambientais - Este indicador apresenta os gastos realizados em projetos direcionados ao meio ambiente;

5. Indicadores dos Recursos Humanos - Neste aspecto são demonstrados os dados relacionados aos colaboradores da organização. Dentre os indicadores, tem-se: a quantidade e perfil dos empregados, como por exemplo, o $\mathrm{n}^{\mathrm{o}}$ de funcionários, $\mathrm{n}^{\mathrm{o}}$ de admitidos, $\mathrm{n}^{\mathrm{o}}$ de mulheres colaboradoras da empresa, $\mathrm{n}^{\circ}$ de empregados portadores de deficiência, \% de mulheres nos cargos de chefia, dentre outras, subsídios considerados ressaltantes ao exercício da responsabilidade social;

6. Informações importantes quanto ao exercício da cidadania organizacional - Expõem os dados que apresentam a preocupação pela conservação de um ambiente de trabalho e da participação dos colaboradores em projetos e benefícios da entidade. Abordando, dentre outros aspectos: a afinidade entre a maior e menor remuneração, o número de acidentes de trabalho, bem como, o fato da empresa ouvir os funcionários.

7. Outras Informações - Nesta seção do balanço social a empresa tem autonomia para relacionar as informações consideradas como relevantes, no tocante ao seu aspecto social.

Com base na estrutura do Modelo IBASE de balanço social é possível que o mesmo garanta certo padrão de informações, o qual possibilitará o desempenho de práticas sociais por parte das empresas. Se a forma de apresentação das informações não seguir um padrão mínimo, torna-se difícil uma avaliação adequada da função social da empresa ao longo dos anos. A predominância de dados que possam ser expressos em valores financeiros ou de forma quantitativa é fundamental para enriquecer este tipo de demonstrativo.

É evidente que correlacionar fatores financeiros com fatos sociais é uma tarefa complexa, porém os indicadores propostos pelo modelo IBASE ajudam às análises comparativas pela própria empresa ao longo do tempo, possibilitam também a comparação com outras do mesmo setor, ou até mesmo de setores diversos. No modelo sugerido pelo IBASE, a sociedade e o mercado são os grandes auditores do processo e dos resultados alcançados.

\subsection{Selo IBASE do Balanço Social}

Em 1998, para estimular a participação de um maior número de corporações, o IBASE lançou o Selo Balanço Social IBASE/Betinho. O selo é atribuído anualmente a todas as empresas que publicam o balanço social no modelo sugerido pelo IBASE, dentro da metodologia e dos critérios propostos. Em 2006 o IBASE deu início ao processo de consulta pública, para assim, analisar melhor quais das empresas solicitante do selo teriam direito de usá-lo, através dessa metodologia a sociedade civil ganhou mais espaço para se manifestar, pois durante o período de dois (2) meses os balanços sociais das empresas solicitantes da certificação ficam expostos à sociedade, para que a mesma opine ou faça denuncias sobre os

REUNIR - Revista de Administração, Contabilidade e Sustentabilidade - Vol. 2, nº 1, p.72-86, Jan-Abr/2012. 
tais balanços.

Durante o processo de consulta pública, uma equipe do IBASE analisa e verifica a procedência e a veracidade das informações recebidas, a autenticidade das pessoas e organizações, além do conteúdo das mensagens. Quando as denúncias representam risco ou impacto negativo para os funcionários, consumidores, sociedade e meio ambiente, e que tem alguma ação civil pública fundamentando o fato; as mesmas eram direcionadas para as empresas convidando-as as esclarecer os fatos. Em caso, de não esclarecimento a empresa perde o direito de receber e utilizar o selo. Este fato aconteceu com algumas empresas: Cia de Saneamento do Distrito Federal (CAESB), Cia Paranaense de Energia Elétrica (COPEL), Itaipu, Petrobras, Centrais Elétricas de Santa Catarina (CELSC), Descartáveis Zanata e Jalles Machado, que perderam o direito ao selo, devido a processos judiciais relacionados a danos ao meio ambiente (MELO, 2006).

O Gráfico 1 demonstra a evolução quantitativa das empresas que receberam o selo IBASE DE 1998 a 2007. Nos dois primeiros anos, 1998 e 1999, de existência da certificação, todas as empresas solicitantes receberam o direito de ostentá-la. O ano de 2000 foi o que apresentou o menor número de empresas recebedoras do selo, tanto em número 08 (oito) instituições, como em percentual, é pertinente levar em consideração, que menos de $10 \%$ das empresas solicitantes do selo tiveram o direito de tê-lo. Durante os anos de 2002 a 2006 o percentual de empresas que receberam o direito de uso do selo com relação às empresas solicitante cresceu significativo, chegando ao ano de 2006, a mais de 95\% das empresas solicitante. Porém, em 2007 o número de empresas que receberam o selo IBASE de balanço social foi reduzido em mais de $65 \%$ se comparado com o ano de 2006.

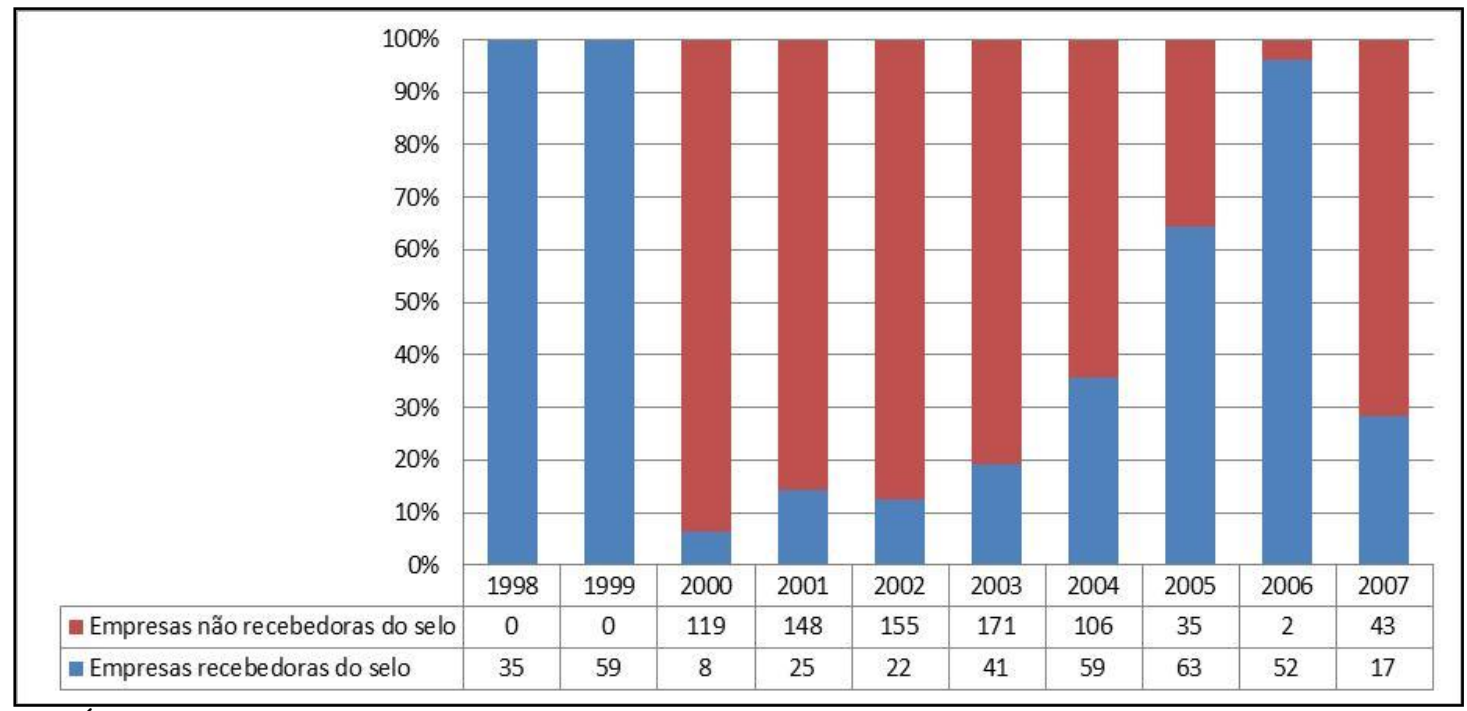

GRÁFICO 1- Evolução do quantitativo de empresas que receberam o Selo IBASE de Balanço Social. Fonte: Elaboração própria dos autores com base em Yuri(2007) e Mansur e Torres (2008).

Em entrevista concedida a Alves (2007) o Coordenador do Projeto Balanço social e Responsabilidade Social Corporativa do IBASE, Ciro Torres, explicou que a queda do número de empresas que receberam o selo teve por motivo o aumento do rigor do Instituto para selecionar as empresas que receberiam o selo. Ainda segundo Alves (2007) Ciro Torres comentou que o aumento do rigor se deu em razão dos dirigentes do órgão terem resolvido 'dizer não a relatórios que não mostravam evolução das empresas em aspectos sociais'. Um

REUNIR - Revista de Administração, Contabilidade e Sustentabilidade - Vol. 2, no 1, p.72-86, Jan-Abr/2012. 
exemplo do aumento desse rigor foi o fato de que em 2007 o IBASE fixou norma de que as empresas solicitantes do selo teriam que publicar nos seus balanços sociais a garantia de 2 a $5 \%$ de seus postos de trabalho para profissionais com deficiência, tomando com base as recomendações do decreto 3.298/09 (MANSUR; TORRES, 2008).

Para Ciro Torres (apud Melo, 2006, p.1) "as empresas que recebem o selo demonstram que não tem receio da transparência, que estão abertas a receberem críticas e a serem observadas pela sociedade". Este selo não garantirá que a empresa seja classificada como socialmente e ambientalmente responsável. Neste sentido, Gonzalez (2006, p.1) reforça a função do selo quando afirma que o mesmo serve para "atestar que a empresa deu transparência àquele dado, não omitiu informações e está disposta a se submeter a um olhar mais critico da sociedade". Através deste selo, as empresas podem mostrar - em seus anúncios, embalagens, balanço social, sites e campanhas publicitárias - que investem em educação, saúde, cultura, esportes e meio ambiente. O Selo Balanço Social IBASE/Betinho demonstra que a empresa já deu o primeiro passo para tornar-se uma verdadeira empresacidadã, comprometida com a qualidade de vida dos funcionários, da comunidade e do meio ambiente; apresenta publicamente seus investimentos internos e externos através da divulgação anual do seu balanço social.

\section{PROCEDIMENTOS METODOLÓGICOS}

Esta pesquisa é do tipo descritivo e exploratório. Descritiva por descrever as características das informações evidenciadas nos Balanços Sociais das empresas em estudo. E exploratória por abordar um tema cujos conhecimentos ainda são relativamente pouco sistematizados, portanto, carente de análises mais detalhadas.

Quanto aos meios, a pesquisa enquadra-se como documental, onde foram coletados dos Balanços Sociais (documentos) dos 132 relatórios das 96 empresas que receberam o selo IBASE nos anos de 2005, 2006 e 2007.

Os balanços sociais foram coletados no sítio denominado balançosocial.org, endereço eletrônico que contém os balanços sociais, bem como a listas das empresas contempladas com o selo IBASE de balanço social, desde o princípio das certificações instituídas por este instituto.

Os balanços sociais encontrados foram cuidadosamente analisados, levando-se em consideração os objetivos desta pesquisa. A fim de analisar e apresentar os dados do estudo confeccionou-se um formulário de coleta de dados com base no modelo de Balanço Social do IBASE. Este formulário foi dividido em 05 (cinco) partes. A primeira possibilitou mapear os indicadores sociais internos; a segunda possibilitou evidenciar quais os indicadores sociais ambientais; a terceira parte, evidência os indicadores sociais externos; a quarta buscou verificar se os Balanços Sociais pesquisados apresentavam informações sobre o Valor Adicionado, onde este se encontra qual o valor e como está distribuído no demonstrativo; a quinta parte buscou coletar informações sobre o corpo funcional. Em seguida os dados coletados foram tabulados no aplicativo Statistical Package for the Social Sciences (SPSS) for Windows versão 16.0. Este aplicativo auxiliou na confecção das tabelas, as quais são apresentadas na seção dos resultados da pesquisa, e principalmente a análise cruzada dos dados.

REUNIR - Revista de Administração, Contabilidade e Sustentabilidade - Vol. 2, nº 1, p.72-86, Jan-Abr/2012. 


\section{APRESENTAÇÃO E DISCUSSÃO DOS RESULTADOS}

Esta seção apresenta os resultados dos dados empíricos encontrados a partir da análise realizada nos 132 balanços sociais que obtiveram o Selo IBASE no período de 2005 à 2007.

\subsection{Indicadores sociais voltados para o público interno (Funcionários)}

Com relação à divulgação dos indicadores internos, os dados da tabela 1 demonstram que dos demonstrativo 99\% (131) divulgam informações sobre Educação, 98\% (130) divulgam informações sobre Saúde e Segurança+ medicina do trabalho e participação nos lucros ou resultados; já 96\% (127) divulgam sobre capacitação e desenvolvimento profissional; 94\% (124) dos balanços apresentam dados sobre creches ou auxílio-creche e outros benefícios; 93\% (123) dos Balanços sociais publicados divulgam informações sobre previdência privada; 92\% (121) dos Balanços fornecem dados sobre incentivos à cultura. Quanto ao indicador vale transporte e indenizações trabalhistas, tem-se que 99\% (131) não divulgam tais informações; $100 \%$ (132) também não informaram sobre gratificação de férias e programas de incentivo ao desligamento. É importante ressaltar, que os gastos com vale transporte sem ser excedente e indenizações trabalhistas configuram como obrigações empresariais e não uma ação social ou uma ação de responsabilidade social.

Tabela 1 - Indicadores Internos apresentados nos Balanços Sociais pelas empresas que receberam o Selo IBASE no período de 2005 a 2007.

\begin{tabular}{|c|c|c|c|c|c|c|c|c|}
\hline \multirow{3}{*}{ Indicadores por Ranking } & \multicolumn{6}{|c|}{ Ano } & \multirow{2}{*}{\multicolumn{2}{|c|}{ TOTAL }} \\
\hline & \multicolumn{2}{|c|}{2007} & \multicolumn{2}{|c|}{2006} & \multicolumn{2}{|c|}{2005} & & \\
\hline & Ocor. & $\%$ & Ocor. & $\%$ & Ocor. & $\%$ & Ocor. & $\%$ \\
\hline Educação & 17 & 100 & 52 & 100 & 62 & 98 & 131 & 99 \\
\hline Saúde & 17 & 100 & 51 & 98 & 62 & 98 & 130 & 98 \\
\hline Segurança + Medicina Trabalho & 17 & 100 & 52 & 100 & 61 & 97 & 130 & 98 \\
\hline Participação nos Lucros ou Resultado & 17 & 100 & 51 & 98 & 62 & 98 & 130 & 98 \\
\hline Capacitação e Desenvolvimento Profissional & 17 & 100 & 51 & 98 & 59 & 94 & 127 & 96 \\
\hline Creches ou Auxílio-creches & 17 & 100 & 50 & 96 & 57 & 90 & 124 & 94 \\
\hline Outros Benefícios & 17 & 100 & 50 & 96 & 57 & 90 & 124 & 94 \\
\hline Previdência Privada & 17 & 100 & 49 & 94 & 57 & 90 & 123 & 93 \\
\hline Interno de Cultura & 17 & 100 & 47 & 90 & 57 & 90 & 121 & 92 \\
\hline Vale Transporte Excelente & 2 & 12 & 0 & 0 & 1 & 2 & 3 & 2 \\
\hline Vale Transporte & 0 & 0 & 1 & 2 & 0 & 0 & 1 & 1 \\
\hline Indenizações Trabalhistas & 0 & 0 & 0 & 0 & 1 & 2 & 1 & 1 \\
\hline
\end{tabular}

Fonte: Elaborado com base na pesquisa documental (2011)

A Tabela 2 aponta os indicadores do corpo funcional utilizados pelas empresas que receberam o selo IBASE no período de 2005 a 2007. Todas as empresas recebedoras do selo apresentaram os indicadores relativos: às admissões durante o período, número de mulheres que trabalharam na empresa, durante o período de 2006 a 2007; todavia, em 2007 apenas $82 \%$ da amostra apresentaram esses mesmos indicadores. 
Tabela 2 - Indicadores do Corpo funcional apresentados nos Balanços Sociais pelas empresas que receberam o Selo IBASE no período de 2005 a 2007.

\begin{tabular}{|c|c|c|c|c|c|c|c|c|}
\hline \multirow{3}{*}{ Indicadores por Ranking } & \multicolumn{6}{|c|}{ Ano } & \multirow{2}{*}{\multicolumn{2}{|c|}{ TOTAL }} \\
\hline & \multicolumn{2}{|c|}{2007} & \multicolumn{2}{|c|}{2006} & \multicolumn{2}{|c|}{2005} & & \\
\hline & Ocor. & $\%$ & Ocor. & $\%$ & Ocor. & $\%$ & Ocor. & $\%$ \\
\hline N. de Empregados ao Final do Período & 14 & 82 & 52 & 100 & 63 & 100 & 129 & 98 \\
\hline N. de Admissões Durante o Ano & 14 & 82 & 52 & 100 & 63 & 100 & 129 & 98 \\
\hline N. de Mulheres que trabalham na empresa & 14 & 82 & 52 & 100 & 63 & 100 & 129 & 98 \\
\hline N. de Estagiários & 14 & 82 & 51 & 98 & 62 & 98 & 127 & 96 \\
\hline N. de Empregados Terceirizados & 14 & 82 & 49 & 94 & 60 & 95 & 123 & 93 \\
\hline
\end{tabular}

Fonte: Elaborado com base na pesquisa documental.

Vale salientar que nenhum dos balanços que recebeu o selo IBASE evidenciou a informação, número de demissões durante o ano, durante o período estudado. Essa ocorrência chama atenção por se tratar de uma informação entendida como negativa. Todavia, a maior parcela dos indicadores foi demonstrada por mais de $80 \%$ dos balanços estudados, mostrando indícios de padronização. Somente uma empresa apresentou o indicador relativo ao número de negros que trabalham na empresa e que ocupam cargo de chefia.

\subsection{Indicadores sociais voltados para o público externo (Comunidade)}

A Tabela 3 aponta os indicadores sociais utilizados pelas empresas que receberam o selo IBASE de responsabilidade social no período de 2005 a 2007. Com base no instrumento mencionado, tem-se que 93\% (123) Balanços Social demonstraram dados relativos a outros benefícios; 87\% (115) apresentaram o indicador educação; 85\% (112) dos balanços publicaram informação sobre Cultura; quanto ao indicador esporte e lazer tem-se $82 \%$ (108) apresentaram esses dados em seus Balanços; já 77\% (101) balanços apresentaram informações sobre Saúde e Saneamento e Combate à fome e segurança alimentar.

Tabela 3 - Indicadores Externos apresentados nos Balanços Sociais pelas empresas que receberam o Selo IBASE no período de 2005 a 2007.

\begin{tabular}{|c|c|c|c|c|c|c|c|c|}
\hline \multirow{3}{*}{ Indicadores por Ranking } & \multicolumn{6}{|c|}{ Ano } & \multirow{2}{*}{\multicolumn{2}{|c|}{ TOTAL }} \\
\hline & \multicolumn{2}{|c|}{2007} & \multicolumn{2}{|c|}{2006} & \multicolumn{2}{|c|}{2005} & & \\
\hline & Ocor. & $\%$ & Ocor. & $\%$ & Ocor. & $\%$ & Ocor. & $\%$ \\
\hline Outros Benefícios & 16 & 94 & 48 & 92 & 59 & 94 & 59 & 94 \\
\hline Educação & 15 & 88 & 43 & 83 & 57 & 90 & 57 & 90 \\
\hline Cultura & 15 & 88 & 40 & 77 & 57 & 90 & 57 & 90 \\
\hline Esporte e Lazer & 12 & 71 & 41 & 79 & 55 & 87 & 55 & 87 \\
\hline Saúde e Saneamento & 11 & 65 & 36 & 69 & 54 & 86 & 54 & 86 \\
\hline Combate à fome e segurança alimentar & 12 & 75 & 36 & 69 & 53 & 84 & 53 & 84 \\
\hline Alimentação & 1 & 6 & 1 & 2 & 2 & 3 & 2 & 3 \\
\hline Habitação & 1 & 6 & 1 & 2 & 1 & 2 & 1 & 2 \\
\hline Geração de Trabalho e Renda & 0 & 0 & 1 & 2 & 1 & 2 & 1 & 2 \\
\hline Reassentamento de Família & 0 & 0 & 1 & 2 & 1 & 2 & 1 & 2 \\
\hline
\end{tabular}

Fonte: Elaborado com base na pesquisa documental 
Em algumas áreas os investimentos no social são menores, portanto, com base nos balanços sociais analisados constatou-se que: o indicador Habitação foi informado por 2\% (3) dos demonstrativos estudados; o indicador: alimentação foi mencionada em 3\% (4) informaram dados do indicador alimentação; os indicadores de Geração de trabalho e Renda e reassentamento de famílias foram mencionados apenas por 2\% (2) Balanços Sociais.

\subsection{Indicador valor adicionado e indicadores sociais voltados para o meio ambiente}

Todos os balanços sociais que receberam o selo apresentaram o indicador "valor adicionado', que representa a riqueza gerada por uma empresa durante um determinado período. Este indicador é apresentando na seção do Modelo IBASE chamada de: informações relevantes quanto ao exercício da cidadania. Os achados da pesquisa demonstraram que além de evidenciar o indicador 'valor adicionado a distribuir' em valor monetário, aproximadamente $94 \%$ dos balanços estudados o fizeram na forma de distribuição percentual.

Ao longo da pesquisa procurou-se investigar quais eram os principais indicadores ambientais utilizados para evidenciar a responsabilidade socioambiental. A análise da tabela 4 revela que os indicadores ambientais de investimento relacionados com produção /operação tiveram cento e vinte e quatro (124) com ocorrência de 94\% dos casos, seguido do indicador de investimento em Programas/Projetos externos que foram demonstrados por $92 \%$ dos Balanços Sociais pesquisados. Em seguida tem-se o indicador de Passivos e Contingências Ambientais onde 3 (2\%) Balanços divulgaram tal informação.

Tabela 4 - Indicadores Ambientais apresentados nos Balanços Sociais pelas empresas que receberam o Selo IBASE no período de 2005 a 2007.

\begin{tabular}{l|c|c|c|c|c|c|c|c|}
\hline \multirow{2}{*}{ Indicadores por Ranking } & \multicolumn{3}{c|}{ Ano } & \multicolumn{2}{c|}{ TOTAL } \\
\cline { 2 - 10 } & \multicolumn{2}{|c|}{$\mathbf{2 0 0 7}$} & \multicolumn{2}{|c|}{$\mathbf{2 0 0 6}$} & \multicolumn{2}{c|}{$\mathbf{2 0 0 5}$} & \multicolumn{2}{c}{} \\
\cline { 2 - 10 } & Ocor. & $\%$ & Ocor. & $\%$ & Ocor. & $\%$ & Ocor. & $\%$ \\
\hline Investimento Relacionados com Produção/ Operação & 16 & 94 & 49 & 94 & 59 & 94 & 124 & 94 \\
\hline Programas/Projetos Externos & 16 & 94 & 50 & 96 & 56 & 89 & 122 & 92 \\
\hline Passivos e Contingências Ambientais & 0 & 0 & 2 & 4 & 1 & 2 & 3 & 2 \\
\hline
\end{tabular}

Fonte: Elaborado com base na pesquisa documental

Ainda com relação aos indicadores ambientais notou-se que nenhum dos Balanços Sociais analisados divulgou os seguintes indicadores ambientais: investimentos e gastos com a educação ambiental para funcionários; investimentos e gastos com a educação ambiental para comunidade; investimentos e gastos com outros objetos ambientais, quantidade de processos ambientais, administrativos e judiciais movidos contra a entidade; e valor das multas e indenizações relativas à matéria ambiental, determinadas administrativa e/ou judicialmente.

\section{CONSIDERAÇÕES FINAIS}

Para a pesquisa documental foram avaliados cento e trinta e dois (132) balanços sociais de empresas que receberam o selo IBASE de balanço social nos anos de 2005, 2006 e 2007. Quanto à estrutura de indicadores voltados para demonstrar os investimentos sociais nos três públicos: colaboradores internos, comunidade e meio ambiente, o estudo revelou que as empresas recebedoras do selo IBASE utilizaram mais indicadores sociais voltados para

REUNIR - Revista de Administração, Contabilidade e Sustentabilidade - Vol. 2, no 1, p.72-86, Jan-Abr/2012. 
demonstrar a relação da entidade com os seus recursos humanos, incluindo os indicadores do corpo funcional, seguindo com a sociedade e por último com o meio ambiente, sendo, dezessete (17), dez (10) e três (3) indicadores respectivamente.

Os indicadores encontrados nos balanços sociais estudados obtidos demonstraram a intenção das entidades recebedoras do selo IBASE de balanço social destinar recursos para as ações sociais voltadas, em geral, para o público interno. Apesar de muitos dos indicadores serem considerados como obrigatórios por parte da organização, tais como: vale transporte e Indenizações trabalhistas. Ainda com relação aos indicadores sociais voltados para mostrar a relação das entidades recebedoras do selo com seus colaboradores, faz-se necessário salientar que nenhum dos balanços que receberam o selo IBASE evidenciou a informação número de demissões durante o ano, durante o período estudado. Essa ocorrência chama atenção por se tratar de uma informação entendida como negativa.

Ao buscar os indicadores sociais voltados para a comunidade pelas empresas que receberam certificação do IBASE, encontrou-se 10 indicadores, com destaque aos seguintes: Educação (90\%), cultura (90\%), Esporte e lazer (87\%). Por sua vez, correlacionado os indicadores de meio ambiente, constata-se uma carência indicadores, que podem indicar também na carência de investimento sociais nessa área. Por fim, conclui-se que as empresas que receberam o selo IBASE de balanço social apresentam através de um conjunto de indicadores padrões suas práticas de ações de responsabilidade Social.

\section{REFERENCIAS}

ALVES, A. Sustentabilidade: despenca número de empresas com selo IBASE. Jornal Gazeta Mercantil, São Paulo, p.B4, 13 ago. 2007.

AMAZONAS. Lei n. 2.843, de 31 de outubro de 2003. Cria o Certificado de Responsabilidade Social para empresas estabelecidas no âmbito do Estado do Amazonas e dá outras providências. Acesso em 08 Jan 2011.

BERNARDO, Tereza N. da C.; SILVA, Ana P. F. da; FALK, James. Indicadores de balanço social como ferramenta para demonstrar as práticas de responsabilidade socioambiental: um estudo realizado no setor elétrico. In: Anais... do $10^{\circ}$ ENCONTRO NORDESTINO DE CONTABILIDADE, 10, 2011, Salvador. CD-ROM.

BRASIL. Projeto de Lei $n^{o}$ 1.305. Dispõe sobre a regulamentação da responsabilidade social das sociedades empresariais nacionais e estrangeiras que atuam no Brasil. Brasília: Câmara dos Deputados, 2003.

CANZIAN, Marcela. Balanço Social para as sociedades cooperativas. Revista Eletrônica de Contabilidade do Curso de Ciências Contábeis da UFSM. V.1, n.1, p.28-41, dez/2004fev/2005.

CARVALHO, Fernanda de M.; SIQUEIRA, José M. De. Os indicadores ambientais nas normas de Balanço Social. In: CONTABILIDADE AMBIENTAL E RELATÓRIOS SOCIAIS. São Paulo: Atlas, 2009, p.92-111. 
CUNHA, Jacqueline V. da; RIBEIRO, Maisa de S. Evolução e diagnosóstico atual do balanço social. In: Anais... CONGRESSO USP DE CONTROLADORIA E CONTABILIDADE, 4, 2004, São Paulo. Disponivel em: < www.congressousp.fipecafi.org/artigos42004/281.pdf >. Acesso em: 20 Mar, 2011.

FREIRE, Fátima de S., REBOUÇAS, Tereza R. da S. Uma descrição sucinta do balanço social francês, português, belga e brasileiro. In: SILVA, César Augusto Tibúrcio, FREIRE, Fátima de Souza (organizadores). Balanço social: teoria e prática. São Paulo: Atlas, 2001.

GONZALER, A. Selo Balanço Social: sociedade civil ganha espaço para se manifestar. Jornal O Globo, São Paulo, p.10C, 4 set. 2006.

KRAEMER, Maria E. P.. TINOCO, João E. P. Contabilidade e Gestão Ambiental. São Paulo: Atlas, 2008.

KROETZ, Carlos. E. S. Balanço social: teoria e prática. São Paulo: Atlas, 2000.

MANSUR, Cláudia; TORRES, Ciro. Balanço Social - Dez anos: o desafio da transparência. Rio de Janeiro: IBASE, 2008.

MELO, L. Transparência: IBASE faz consulta pública para conceder selos. Jornal Valor Econômico, São Paulo, p.F2, 22-24 set. 2006.

MATO GROSSO. Lei $n{ }^{\circ} 7.687$ de 25 de junho de 2002. Cria o Certificado de Responsabilidade Social no Estado de Mato Grosso e dá outras providências. Disponível em:<http://www.al.mt.gov.br/ v2008/Raiz\%20estrutura/responsabilidadesocial/>. Acesso em 08 Jan 2011.

MIRANDA, Luiz C.; SILVA, Ana C. M. da; FEITOSA, Patricia B. M.; OLIVEIRA, Fernando S. de; LIBONATI, Jeronymo J.: Balanço Social no Brasil: como as empresas estão divulgando sua responsabilidade social. In: 13thAsian Pacific Conference of International Accounting Issues; 2001.

OLIVEIRA, José A. P. de. Uma avaliação dos balanços sociais das 500 maiores. Revista de Administração de Empresas (Eletrônica), São Paulo, v.4, n. 1, Art.2, jan/jul, 2005.

RIO GRANDE DO SUL. Lei $n^{o} 11.440$, de 18 de janeiro de 2000. Cria o Certificado Responsabilidade Social - RS - para empresas estabelecidas no âmbito do Estado do Rio Grande do Sul e dá outras providências. Disponível em: $\langle$ http://www.al.rs.gov.br/ >.Acesso em 08 Jan 2011.

RIZZI, Fernanda B. Balanço Social e ação de responsabilidade social nas empresas. In: INSTITUTO ETHOS: Prêmio Ethos Valor. Vários autores. Responsabilidade social das empresas: a contribuição das universidades. São Paulo: Editora Fundação Petrópolis, 2002.

REUNIR - Revista de Administração, Contabilidade e Sustentabilidade - Vol. 2, nº 1, p.72-86, Jan-Abr/2012. 
TORRES, Ciro. Responsabilidade social das empresas (RSE) e balanço social no Brasil. In: SILVA, César Augusto Tibúrcio, FREIRE, Fátima de Souza (organizadores). Balanço social: teoria e prática. São Paulo: Atlas, 2001.

TREVISAN, Fernando A.. Balanço Social como instrumento de marketing. Revista de Administração de Empresas (Eletrônica), São Paulo, v.1, n. 1, p.1-12, jan/jul, 2002.

YURI, Myahira. O Balanço social como fator de diferenciação para obtenção de crédito junto ao BNDS: uma proposta de aplicabilidade. Dissertação (Mestrando em Ciências Contábeis), Programa de Pós-graduação em Ciências Contábeis da UERJ, Universidade Estadual do Rio de Janeiro, Rio de Janeiro, 2007. 